\title{
HUBUNGAN JENIS PEKERJAAN IBU DENGAN PEMBERIAN ASI PADA BAYI DI PUSKESMAS RANOMUUT MANADO
}

\author{
Edward R Koba \\ Sefti S Rompas \\ Vandri D Kalalo \\ Program Studi Ilmu Keperawatan Fakultas Kedokteran \\ Universitas Sam Ratulangi Manado \\ Email : edwardfarm01@gmail.com
}

\begin{abstract}
Exclusive breastfeeding is not giving the baby food or other drinks, other than breastfeeding. Work is generally a time-consuming activity for the mother. One of the causes of the failure of exclusive breastfeeding is working mothers. The purpose of this research was to determine the relation between the type of work of mothers with exclusive breastfeeding to infants at Ranomuut Manado Health Center. Research Design This type of research uses an analytical survey type with a cross sectional approach. The number of samples is 39 people using purposive sampling technique. The data was collected using by questionnaire. The analysis of the data using Pearson Chi-square statistical test. The results showed that mothers with the most types of work were IRT (51.3), most babies received exclusive breastfeeding for (48.7\%) and the results of statistical tests obtained $p=0.024<0.05$. The Conclusion of this research are there is a correlation between the type of work of mothers with exclusive breastfeeding for infants at Ranomuut Manado Health Center.
\end{abstract}

Keywords: Type of works, Exclusive Breastfeeding.

Abstrak : Menyusui eksklusif adalah tidak memberikan bayi makanan atau minuman lain, selain menyusui. Bekerja umumnya merupakan kegiatan yang menyita waktu bagi ibu. Salah satu penyebab belum berhasilnya pemberian ASI Eksklusif adalah ibu bekerja. Tujuan Penelitian ini bertujuan untuk mengetahui hubungan jenis pekerjaan ibu dengan pemberian ASI Eksklusif pada bayi di Puskesmas Ranomuut Manado. Desain Penelitian Jenis penelitian ini menggunakan jenis penelitian survey analitik dengan pendekatan cross sectional. Jumlah sampel 39 orang dengan menggunakan teknik sampel purposive sampling. Alat pengumpulan data berupa kuesioner. Analisa data menggunakan uji statistic Pearson Chi-square. Hasil Penelitian didapatkan bahwa ibu dengan jenis pekerjaan paling banya yaitu sebagai IRT $(51,3)$, sebagian besar bayi mendapatkan ASI Eksklusif sebesar $(48,7 \%)$ dan hasil uji statistic didapatkan nilai $p=0,024<0,05$. Kesimpulan ada hubungan jenis pekerjaan ibu dengan pemberian ASI Eksklusif pada bayi di Puskesmas Ranomuut Manado. Kata Kunci : Jenis Pekerjaan ibu, ASI Eksklusif 


\section{PENDAHULUAN}

Menyusui eksklusif adalah tidak memberikan bayi makanan atau minuman lain, termasuk air putih, selain menyusui (WHO, 2015). ASI (Air Susu Ibu) mengandung gizi yang tinggi yang sangat bermanfaat untuk kesehatan bayi, WHO (World Health Organization) merekomendasikan bayi mendapat ASI Eksklusif selama 6 bulan (KEMENKES RI, 2015). ASI Eksklusif memiliki kontribusi yang besar terhadap tumbuh kembang dan daya tahan tubuh anak, anak yang diberi ASI Ekslusif akan tumbuh dan berkembang secara optimal dan tidak mudah sakit. Hal tersebut sesuai dengan kajian global "The Lancet Breastfeeding Series, 2016" telah membuktikan bahwa menyusui secara Eksklusif menurunkan angka kematian karena infeksi sebanyak $88 \%$ pada bayi berusia kurang dari 3 bulan.

Menyusui bayi sudah menjadi budaya di Indonesia, namun upaya meningkatkan perilaku ibu menyusui ASI Eksklusif masih diperlukan karena pada kenyataannya praktek pemberian ASI Eksklusif belum dilaksanakan sepenuhnya. Salah satu penyebab belum berhasilnya pelaksanaan ASI Eksklusif di Indonesia adalah faktor ibu yang bekerja, meski itu bukan satusatunya faktor penyebab kegagalan. Ibu yang bekerja, dalam upaya pemberian ASI Eksklusif seringkali mengalami hambatan karena singkatnya masa cuti hamil dan melahirkan mengakibatkan sebelum masa pemberian ASI Eksklusif berakhir mereka sudah kembali bekerja, inilah yang menjadikan bayi tidak memperoleh ASI secara Eksklusif, serta banyak ibu yang bekerja beranggapan bahwa ASI nya tidak mencukupi kebutuhan bayi saat ibu bekerja sehingga ibu-ibu memberikan ASI tambahan berupa susu formula (Khasanah, 2011).
Laporan UNICEF (United Nation Children Fund) tahun 2011 dalam World Breastfeeding Week (2012), sebanyak 136,7 juta bayi dilahirkan diseluruh dunia dan hanya $32,6 \%$ dari mereka yang mendapat ASI secara eksklusif pada usia 0 sampai 6 bulan pertama. Data Profil Kesehatan Indonesia tahun 2016, jumlah bayi 0-6 bulan di Indonesia adalah 4.770.444, sedangkan yang mendapatkan ASI eksklusif hanya 2.576.040 atau 54\%. Pada tahun 2016, di Provinsi Sulawesi Utara bayi usia 0-6 bulan yang mendapatkan ASI eksklusif sebesar 47,9\% atau hanya 19.645 bayi dari total jumlah bayi usia 0-6 bulan sebesar 41.014.

Data survei BPS tahun 2017, jumlah angkatan kerja wanita terus meningkat setiap tahunnya. Saat ini dari 128,06 juta, $50,89 \%$ merupakan pekerja perempuan. Secara fisiologis kelompok kerja perempuan mengalami siklus haid, hamil dan menyusui yang memerlukan fasilitasi agar pekerjaan tidak terganggu dan kondisi fisik lainnya tidak mengurangi kinerja (KEMENKES RI, 2015).

Ibu bekerja selama waktu kerja 8 jam, ini berdampak ibu tidak memiliki waktu yang cukup untuk menyusui, oleh karena itu, program ASI (Air Susu Ibu) secara Eksklusif di tempat kerja merupakan terobosan yang dapat meningkatkan cakupan ASI Eksklusif Nasional (KEMENKES, 2015). Dari hasil observasi ditemukan bahwa sekitar 51,3\% tidak diberikan ASI Eksklusif. Hal inilah yang melatarbelakangi peneliti untuk mengetahui lebih jauh tentang hubungan jenis pekerjaan dengan pemberian ASI Eksklusif di Puskesmas Ranomuut Manado.

\section{METODE PENELITIAN}

Desain penelitian yang digunakan adalah rancangan studi cross sectional yang penelitiannya atau pengumpulan data dilakukan secara bersama-sama atau sekaligus (Notoatmodjo, 2012). Penelitian ini dilaksanakan di Puskesmas Ranomuut Manado. Penelitian telah dilaksanakan pada bulan Oktober-Desember 2018. 
Populasi dalam penelitian ini adalah 169 orang dengan jumlah sampel yang bersedia menjadi responden sebanyak 39 orang. Teknik pengambilan sampel yang digunakan adalah puposive sampling; dimana pengambilan sampel yang didasarkan pada kehendak peneliti yang disesuaikan dengan tujuan serta kriteria yang sudah ditentukan (Setiadi, 2013). Total sampel dalam penelitian ini yaitu 39 sampel, dengan Instrumen yang digunakan adalah Kuesioner, terdiri dari 8 pertanyaan. Skala pengukuran yaitu skor 1-3 untuk pertanyaaan tentang jenis pekerjaan ibu dan pemberian asi diberikan skor $0-1$.

Data yang terkumpul diolah dan dianalisis dengan menggunakan program analisa data komputer. Untuk mendapatkan data yang benar dan mempermudah proses pengolahan data, dilakukan tahapan editing, coding, tabulating, cleaning (Nursalam, 2008). Analisis data dalam penelitian ini yaitu analisis univariat dan bivariat. Analisis univariat dilakukan terhadap setiap variabel independen dan variabel dependennya untuk mengetahui karakteristik penelitian dilakukan dengan menganalisis variabel-variabel yang ada secara deskriptif dengan menghitung distribusi frekuensi dan proporsinya. Analisis bivariat dilakukan untuk melihat adanya kemaknaan hubungan antara variabel bebas dengan variabel terikat. Untuk membuktikan hipotesis penelitian, peneliti menggunakan uji Person ChiSquare Dengan nilai $\alpha=0,05$. Bila nilai $P$ nilai $<\alpha$ maka keputusannya adalah Ho ditolak. Dalam melakukan penelitian, peneliti memperhatikan masalah-masalah etika penelitian yang meliputi ; menghormati harkat dan martabat manusia (respect for human dignity), menghormati privasi dan kerahasiaan subjek penelitian (respect for privacy and confitentiality), menghormati keadilan dan inklusivitas (respect for justice and inclusiveness), peneliti memperhitungkan manfaat dan kerugian yang ditimbulkan (balancing harms and benefit (Nursalam, 2008).

\section{HASIL dan PEMBAHASAN}

1. Karakteristik Responden

Penelitian ini didapatkan bahwa sebagian besar responden adalah sebagai IRT dan yang paling sedikit bekerja sebagai PNS, TNI/POLRI. Lingkungan pekerjaan seseorang dapat memberikan pengalaman baik secara langsung maupun tidak langsung, interaksi dengan lingkungan serta informasi akan mempengaruhi ibu, sehingga ibu tidak mempunyai atau memiliki waktu yang cukup dalam melakukan pemberian ASI secara Eksklusif

2. Hasil Analisis Univariat

Karakteristik data pada responden yakni meliputi jenis pekerjaan ibu dan pemberian ASI Eksklusif

Tabel 1. Distribusi Responden Berdasarkan Jenis Pekerjaan

\begin{tabular}{ccc}
\hline Pekerjaan & n & \% \\
\hline PNS, TNI/POLRI & 7 & 17,9 \\
Karyawan/Wiraswasta & 12 & 30,8 \\
IRT & 20 & 51,3 \\
Total & $\mathbf{3 9}$ & $\mathbf{1 0 0 , 0}$ \\
\hline
\end{tabular}

Sumber: Data Primer, 2018

Data Tabel 1, di atas dapat diketahui bahwa dari 39 responden dalam penelitian ini, jenis pekerjaan ibu terbanyak adalah yang bekerja sebagai IRT sebanyak (51,3\%). Sama seperti penelitian sebelumnya yang dilakukan oleh (Kusmiyati, 2014), dimana dari 59 sampel, sebanyak $43 \quad(73 \%)$ responden tidak bekerja. Hal ini menunjukkan bahwa IRT cenderung memiliki waktu yang cukup dalam pemberian ASI Eksklusif.

Pekerjaan ialah sekumpulan kedudukan atau posisi yang memiliki persamaan kewajiban dan tugas-tugas pokoknya. Dalam arti sempit, istilah pekerjaan digunakan untuk tugas atau kerja yang menghasilkan sebuah karya bernilai imbalan dalam bentuk uang bagi seseorang. Menurut peneliti fenomena ini terjadi karena bekerja umumnya merupakan kegiatan yang menyita waktu bagi ibu-ibu 
yang mempunyai pengaruh terhadap kehidupan keluarga

Tabel 2. Distribusi Responden Berdasarkan pemberian ASI Eksklusif

\begin{tabular}{ccc}
\hline Pemberian ASI & n & \% \\
\hline Tidak Eksklusif & 20 & 51,3 \\
Eksklusif & 19 & 48,7 \\
Total & $\mathbf{3 9}$ & $\mathbf{1 0 0}$ \\
\hline
\end{tabular}

Sumber : Data primer, 2018

Dari Tabel 2, di atas dapat diketahui bahwa sebagian besar responden yang memberikan ASI Eksklusif sebesar (48.7\%). Hasil penelitian ini sejalan yang dilakukan oleh Dahlan (2013) dimana menujukka bhawa sebanyak $55,3 \%$ dari jumlah sampel 47 responden tidak memberikan ASI Eksklusif.

ASI Eksklusif adalah pemberian ASI pada bayi tanpa tambahan cairan lain, seperti susu formula, jeruk, madu, air teh, air putih dan tanpa tambahan makanan padat, misalnya pisang, papaya, bubur susu, biskuit, bubur nasi, tim atau makanan lain selain ASI (Nurkhasanah, 2011). Hasil penelitian ini sebagian besar ibu tidak memberikan ASI Eksklusif yaitu ada yang memberikan ASI ditambah dengan susu formula, dan ada yang memberikan susu formula saja.

3. Analisis Bivariat

Hubungan Jenis Pekerjaan ibu dengan pemberian ASI Eksklusif pada bayi di Puskesmas Ranomuut Manado

Tabel 3. Hubungan Jenis Pekerjaan Ibu dengan Pemberian ASI Eksklusif pada bayi di Puskesmas Ranomuut

\begin{tabular}{|c|c|c|c|c|c|c|c|}
\hline \multirow{3}{*}{ Pekerjaan Ibu } & \multicolumn{4}{|c|}{ Pemberian ASI } & \multirow{2}{*}{\multicolumn{2}{|c|}{ Total }} & \multirow{3}{*}{$\rho$} \\
\hline & \multicolumn{2}{|c|}{$\begin{array}{c}\text { Tidak } \\
\text { Eksklusif }\end{array}$} & \multicolumn{2}{|c|}{ Eksklusif } & & & \\
\hline & $\mathrm{n}$ & $\%$ & $\mathrm{n}$ & $\%$ & $\mathrm{n}$ & $\%$ & \\
\hline PNS, TNI/POLRI & 5 & 71,4 & 2 & 28,6 & 7 & 100 & \\
\hline Karyawan/Wiraswasta & 9 & 75 & 3 & 25 & 12 & 100 & 0,024 \\
\hline IRT & 6 & 30 & 14 & 70 & 20 & 100 & \\
\hline Total & 20 & 51,3 & 19 & 48,7 & 39 & 100 & \\
\hline
\end{tabular}

Data Tabel 3, di atas menunjukkan bahwa dari 39 responden sebagian besar yang memberikan ASI eksklusif adalah dari ibu yang bekerja sebagai IRT. Berdasarkan hasil penelitian diperoleh jenis pekerjaan ibu yang memberikan ASI Eksklusif yaitu PNS, TNI/POLRI sebanyak 2 orang (10,52 $\%)$, Karyawan/Wiraswasta 3 orang (15,78 $\%)$, IRT 14 orang $(73,68 \%)$, sedangkan yang tidak memberikan ASI tidak eksklusif yaitu PNS, TNI/POLRI sebanyak 5 orang (25\%), Karyawan/Wiraswasta 9 orang (45 $\%)$, IRT sebanyak 6 orang (30\%).

Hasil analisis menggunakan uji Pearson Chi-square menunjukan nilai $\rho=$ 0,024 . Tingkat kepercayaan alfa $(\alpha)$ yang digunakan yaitu: 0,05 . Jadi $\rho<\alpha=0,05$ sehingga $\mathrm{Ha}$ diterima artinya terdapat hubungan yang signifikan antara jenis pekerjaan ibu dengan pemberian ASI secara Eksklusif pada bayi.

Kusmiyati (2014), melakukan penelitian hubungan pendidikan dan pekerjaan ibu dengan pemberian makanan pendamping ASI (MP-ASI) pada bayi di Puskesmas Bahu Kecamatan Malalayang Kota Manado, menunjukkan bahwa ibu yang tidak bekerja lebih banyak memberikan ASI eksklusif dibandingkan dengan ibu yang bekerja. Penelitian ini juga dilakukan oleh Fitriyani (2017), dalam pemberian ASI eksklusif di Wilayah Kerja Puskesmas Sipayung, menunjukkan bahwa responden yang tidak bekerja memberikan ASI eksklusif lebih banyak.

Hasil penelitian ini diperoleh sebagian besar responden bekerja sebagai IRT, didapatkan hasil bahwa pemberian ASI dilakukan secara Eksklusif. Adapun faktor yang diperoleh oleh peneliti bahwa IRT memiliki waktu yang cukup untuk memberikan ASI secara Eksklusif. Dibandingkan dengan ibu yang bekerja sebagai PNS, TNI/POLRI dan Karyawan/Wiraswasta.

Hasil penelitian didapatkan bahwa ibu yang bekerja sebagai PNS, TNI/POLRI terdapat 5 orang yang tidak memberikan ASI Eksklusif dan ibu yang bekerja sebagai Karyawan/Wiraswasta sebanyak 9 orang. 
Adapun 5 responden dari total sampel ibu yang bekerja dapat memberikan ASI eksklusif adalah dengan memberikan asi peras. Menurut peneliti fenomena diatas dikarenakan sebagian besar ibu bekerja. Bila sudah bekerja, kadang ibu tidak mau direpotkan dengan kegiatan dalam memompa ASI. Bekerja juga merupakan sumber ketegangan dan stress yang besar bagi para ibu bekerja.

Kondisi fisik dan mental yang lelah setelah bekerja sepanjang hari dapat menghambat kelancaran produksi ASI. Selain itu juga ada faktor budaya setempat yang tidak biasa memberikan ASI eksklusif terhadap bayinya, atau memberikan ASI dengan ditambah minuman lainnya sebelum usia 6 bulan.

\section{SIMPULAN}

1. Jenis pekerjaan ibu di wilayah kerja Puskesmas Ranomuut Manado sebagian besar adalah IRT

2. Pemberian ASI Eksklusif pada bayi di wilayah kerja Puskesmas Ranomuut sebagian besar ASI eksklusif.

3. Ada hubugan antara jenis pekerjaan ibu dengan pemberian ASI eksklusif pada bayi di wilayah kerja Puskesmas Ranomuut Manado.

\section{DAFTAR PUSTAKA}

Badan Pusat Statistik, 2017. Keadaan Ketenagakerjaan Indonesia Agustus (2018) https://tumoutounews.com/wpcontent/uploads/2017/11/DOWNLOA D-DATA.pdf

Dahlan, A (2013). Hubungan Status Pekerjaan dengan Pemberian ASI Eksklusif di Kelurahan Palebon Kecamatan Pedurungan Kota Semarang https://jurnal.unimus.ac.id/index.php/j ur_bid/article/view/1021

Data dan Informasi Profil Kesehatan Indonesia 2016. http://www.depkes.go.id/resources/do wnload/pusdatin/profil-kesehatanindonesia/Profil-Kesehatan-Indonesia- 2016.pdf

Fitriyani, B (2017). Hubungan Pekerjaan Ibu Terhadap Pemberian ASI Eksklusif Pada Bayi

http://ejournal.kopertis10.or.id/index.p hp/endurance/article/viewFile/1699/67 9

KEMENKES RI, (2015). Dukung Ibu Bekerja Beri ASI Eksklusif http://www.depkes.go.id/article/view/ 15091400003/dukung-ibu-bekerjaberi-asi-eksklusif.html

Khasanah, N (2011). ASI atau Susu Formula Ya. Yogyakarta: Flash Books

Kusmiyati (2014). Hubungan Pengetahuan, Pendidikan dan Pekerjaan Ibu dengan Pemberian Makanan Pendamping ASI (MP-ASI) pada Bayi di Puskesmas Bahu Kecamatan Malalayang Kota Manado https://media.neliti.com/media/publica tions/91606-ID-hubunganpengetahuan-pendidikan-dan-peke.pdf

Nurkhasanah, 2011. ASI Atau Susu Formula, Jakarta : Flash Book

Notoatmodjo, S. 2012. Metodologi Penelitian Kesehatan. Rineka Cipta. Jakarta

Nursalam. (2013). Metode Penelitian Ilmu Keperawatan Edisi 3. Salemba Medika. Jakarta.

Setiadi. (2013). Konsep dan Praktik Penulisan Riset Keperawatan. Edisi 2. Yogyakarta : Graha Ilmu

The Lancet, (2016). Series The Lancet Journals. Breastfeeding. https://www.thelancet.com/series/brea stfeeding 
e-journal Keperawatan (e-Kp) Volume 7 Nomor 1, Februari 2019

World Health Organization. (2015). Health

Topics. Breastfeeding. http://www.who.int/topics/breastfeedi ng/en/. World Health Organization, 2015. Nutrition. Breastfeeding.

http://www.who.int/nutrition/topics/ex clusive_breastfeeding/en/. 